\title{
APRENDIZAGEM BASEADA EM PROBLEMAS ENVOLVENDO A TEMÁTICA ALIMENTAÇÃO: REFLEXÕES DECORRENTES DE UM ESTÁGIO EM ENSINO DE QUÍMICA
}

\author{
Mariana Ferrari Bach* \\ Carlos Ventura Fonseca*
}

Resumo: O presente trabalho tem por objetivo analisar as práticas e reflexões de uma estagiária de docência em Química (curso de Licenciatura em Química da Universidade Federal do Rio Grande do Sul), que esteve em atividade de regência em uma instituição escolar pública federal, localizada na região metropolitana de Porto Alegre - RS. A metodologia de aprendizagem baseada em problemas foi utilizada para trabalhar a temática "alimentação saudável" com quatro turmas de cursos técnicos integrados ao Ensino Médio. Foi desenvolvido um estudo qualitativo exploratório, baseado em uma única fonte documental (o relatório de estágio produzido ao final da disciplina), sendo realizada a análise de conteúdo da produção textual citada. Foram obtidas oito categorias de análise emergentes dessa investigação, que deram indicativos de que o estágio propiciou para a professora em formação a constituição de reflexões relevantes a respeito do ofício docente, principalmente no que tange à experimentação de diferentes práticas de ensino-aprendizagem e avaliação, tendo em vista os momentos de construção de conhecimentos protagonizados pelos sujeitos da instituição de ensino onde foi realizado o referido período de regência. A partir dessas categorias, foram construídas algumas asserções de conhecimento, que foram consideradas como desafios a serem transpostos pelos sujeitos e instituições relacionados à área de Educação em Ciências.

Palavras-chave: Aprendizagem baseada em problemas. Alimentação saudável. Ensino de Química. Formação docente.

\section{Introdução}

O estágio docente tem por objetivo aproximar futuros professores da realidade na qual atuarão, fornecendo aquisições teóricas e práticas para que estes exerçam a docência como forma de transformação da realidade (PIMENTA; LIMA, 2012). Durante o período de estágio, o sujeito pode refletir criticamente a respeito de si e envolver-se com o aprendizado (no contexto da sala de aula, da escola, do sistema de ensino e da sociedade), o que permite mudanças no seu modo de pensar, aperfeiçoando sua atuação e sua consciência a respeito da responsabilidade de sua profissão (PIMENTA; LIMA, 2012).

Neste trabalho, pensamos que a formação docente deve ser permeada pela ação pedagógica crítica/ libertadora/ dialógica, através de processos que provoquem a

\footnotetext{
* Pós-doutoranda em Química na Universidade Federal de Pelotas. E-mail: ferrari.mariana32@gmail.com

** Professor Adjunto da Universidade Federal do Rio Grande do Sul, onde atua na Faculdade de Educação. Email: carlos.fonseca@ufrgs.br
} 


\section{\#tear}

problematização acerca de temas importantes para os educandos e a sociedade (realidade) na qual estão inseridos (FREIRE, 1987). Posicionamo-nos, assim como o autor citado, contrariamente ao modelo de educação bancária, que domina as aulas tradicionais e é caracterizado pela imposição acrítica de conteúdos programáticos, sendo marcado pela atuação docente que é limitada pela simples exposição do conhecimento.

Pretendemos, neste trabalho, apresentar e analisar as práticas pedagógicas de uma estagiária de docência em Química (curso de Licenciatura em Química da Universidade Federal do Rio Grande do Sul - UFRGS). As atividades, tendo como referência principal a metodologia conhecida como resolução de problemas (FERNANDES; CAMPOS, 2017), foram desenvolvidas em uma escola pública federal da região metropolitana de Porto Alegre RS, durante seis semanas do ano letivo de 2017.

O trabalho teve como foco os conteúdos conceituais relacionados a biomoléculas, sendo utilizada a temática "alimentação saudável" como forma de contextualização. O referido tema é frequentemente abordado pelas pesquisas da área de ensino de Química, justamente por propiciar muitas conexões com os conceitos científicos atrelados a essa área do conhecimento (FONSECA, 2010; FONSECA; LOGUERCIO, 2013a, 2013b).

Objetivamos, com este artigo, que os resultados obtidos forneçam indicativos das reflexões produzidas pela estudante de licenciatura ao longo desse momento de sua formação inicial, de modo que sejam demonstrados e problematizados, ao menos em parte, os aprendizados teórico-práticos construídos.

\section{Referenciais teóricos}

A partir das ideias de Freire (1987), entendemos que seja possível a atuação e a construção de processos de formação de professores que despertem a leitura crítica do momento histórico e cultural dos sujeitos, concebendo o educador e o educando como seres inconclusos. Na perspectiva freiriana, a atuação docente deve provocar situações nas quais os educandos possam construir diferentes modos de interferir e interpretar o mundo/ os fatos/ os problemas que os cercam.

$\mathrm{O}$ autor defende o desenvolvimento de uma "curiosidade epistemológica" (FREIRE, 1996, p.15), embasada no rigor metódico. Nesse contexto, o educador deve respeitar a presença inicial do saber ingênuo (senso comum), articulando-o como ponto de partida para movimentos de aprendizagem que superem essa forma de conhecimento que pode se estabelecer como um agente dominante e limitador da cidadania. 


\section{\#tear}

Articulado à visão de Freire (1987), este trabalho concebe que o professor de Química possui, como um dos seus desafios principais, despertar o interesse dos sujeitos ao longo das atividades de ensino-aprendizagem (POZO; CRESPO, 2009). Consideramos, ainda, que o alto grau de abstração necessário para a compreensão dos conceitos é um dos fatores que geram dificuldades a serem enfrentadas pelos estudantes nas aulas de Química do ensino médio (FRANÇA; MARCONDES; CARMO, 2009).

Tais dificuldades apontam para a necessidade da utilização de metodologias variadas que consigam contextualizar os conteúdos trabalhados (FONSECA, 2014). Na mesma esteira, devemos ressaltar que, no ambiente escolar, o estudo dessa área de conhecimento tem o objetivo de que os estudantes possam, pelo menos, compreender parte das características do mundo em que vivem (POZO; CRESPO, 2009).

A aprendizagem baseada em problemas, também conhecida como metodologia de resolução de problemas, apresenta-se como uma boa alternativa para trabalhar os mais diversos assuntos em sala de aula, de uma forma não tradicional (POZO; CRESPO, 2009). As pesquisas envolvendo resolução de problemas, no cenário internacional da área de Educação em Química, tendem a constituir-se como pesquisas qualitativas aplicadas que discutem o viés investigativo dos processos de ensino-aprendizagem, havendo, em grande parte, o foco em conteúdos conceituais envolvendo Química Geral e Físico-Química (FERNANDES; CAMPOS, 2017).

Os problemas diferenciam-se dos exercícios por colocarem os estudantes em um papel mais ativo na busca por respostas e, neste caminho, construir conhecimentos. Diferentemente do que ocorre na resolução de exercícios, encontrar uma solução para um problema é uma tarefa mais trabalhosa, uma vez que os estudantes não dispõem imediatamente das ferramentas necessárias, o que requer, dentre outras coisas, movimentos investigativos que as identifiquem (BATINGA; TEIXEIRA, 2009).

\section{Metodologia}

A presente pesquisa pode ser classificada como qualitativa, objetivando a compreensão de "fenômenos educativos e sociais" (ESTEBAN, 2010, p. 127). Foi realizado um estudo exploratório, baseado em uma única fonte documental (o relatório produzido por uma aluna da disciplina de Estágio de Docência em Ensino de Química II, ministrada na Faculdade de Educação da UFRGS). O uso da análise documental torna possível a consulta a fontes que apresentam riqueza de dados e são estáveis ao longo do tempo, caracterizando o contexto do qual são originários (GUBA; LINCOLN, 1981; LÜDKE; ANDRÉ, 1986). 
Foi realizada, com isso, a análise de conteúdo da produção textual citada (FRANCO, 2008). Na primeira etapa do processo analítico, realizamos a leitura flutuante da íntegra do texto, através da qual foram obtidas unidades de registro (frases ou parágrafos) que representassem o entendimento da estagiária sobre diferentes momentos das experiências formativas. Posteriormente, a análise de conteúdo revelou oito categorias emergentes do corpo textual estudado (que serão discutidas nas próximas seções). A partir destas, foram construídas algumas asserções de conhecimento, que foram consideradas como desafios a serem transpostos pela área de Educação em Ciências, tendo em vista os sujeitos e instituições relacionadas.

\section{Resultados e discussões}

O Quadro 1 apresenta as atividades que foram realizadas no período de seis semanas de regência de classe, havendo dois períodos de cinquenta minutos por semana com cada turma.

Quadro 1 - Atividades planejadas pela professora-estagiária

\begin{tabular}{|c|c|}
\hline Semana & Atividades \\
\hline 1 & $\begin{array}{l}\text { a) Aplicação de dois questionários: um para explorar os conhecimentos prévios dos alunos } \\
\text { sobre alimentação, lipídios, proteínas e carboidratos; outro para realizar a caracterização } \\
\text { das turmas; } \\
\text { b) Construção de um mapa conceitual sobre a temática "Alimentação" a partir dos } \\
\text { conhecimentos prévios dos estudantes; } \\
\text { c) Realização de uma atividade em grupo de leitura e interpretação de texto / introdução aos } \\
\text { estudos sobre "Alimentação Saudável". }\end{array}$ \\
\hline 2 & $\begin{array}{l}\text { a) Apresentação de um problema aos estudantes; } \\
\text { b) Formação de grupos; } \\
\text { c) Discussão sobre o problema, realização de pesquisas em materiais de apoio fornecidos } \\
\text { pela estagiária, na internet (no laboratório de Informática) e no livro didático dos alunos; } \\
\text { d) Início da elaboração de um trabalho escrito e de uma apresentação contendo respostas ao } \\
\text { problema. }\end{array}$ \\
\hline 3 & $\begin{array}{l}\text { a) Realização de uma aula expositiva e dialogada, com utilização de slides, sobre } \\
\text { alimentação e nutrientes (biomoléculas); } \\
\text { b) Resolução de exercícios, sendo também abordados assuntos cotidianos (como biodiesel, } \\
\text { gordura trans e saúde). }\end{array}$ \\
\hline 4 & $\begin{array}{l}\text { a) Apresentações orais dos alunos sobre as soluções que encontraram para o problema; } \\
\text { b) Questionamentos e reflexões para sistematização dos conhecimentos. }\end{array}$ \\
\hline 5 & $\begin{array}{l}\text { a) Avaliação escrita referente à aprendizagem dos conteúdos trabalhados nas aulas } \\
\text { anteriores. }\end{array}$ \\
\hline 6 & $\begin{array}{l}\text { a) Aula de recuperação de conteúdos, na qual foram trabalhadas as maiores dificuldades } \\
\text { apresentadas pelos estudantes. }\end{array}$ \\
\hline
\end{tabular}

Fonte: Elaborado pelos autores com base no relatório da estagiária. 
As aulas do estágio foram ministradas para quatro turmas de cursos técnicos integrados ao Ensino Médio, sendo duas turmas do Técnico em Informática ( $3^{\circ}$ e $4^{\circ}$ anos) e duas turmas do Técnico em Eletrônica ( $2^{\circ}$ e $3^{\circ}$ anos). Devido à organização curricular de cada um dos cursos citados e à reestruturação desta, as quatro turmas estavam estudando conteúdos referentes à Química Orgânica.

Após conversas com a Professora Titular das turmas e com o Professor Orientador da disciplina de estágio, o assunto biomoléculas foi o escolhido para ser trabalhado pela estagiária, sendo o principal conteúdo conceitual. Na primeira semana de regência, foi solicitado que os estudantes respondessem a um questionário como forma de coleta de dados, a fim de realizar a caracterização das turmas (Tabela 1).

Tabela 1 - Caracterização das turmas em relação ao número de alunos e faixa etária.

\begin{tabular}{cccc}
\hline Turma & Sigla & Número de Alunos & Faixa Etária \\
\hline $4^{\circ}$ Ano Informática & A & 28 & $17-20$ anos \\
$2^{\circ}$ Ano Eletrônica & B & 18 & $15-19$ anos \\
$3^{\circ}$ Ano Eletrônica & C & 18 & $16-18$ anos \\
$3^{\circ}$ Ano Informática & D & 23 & $16-20$ anos \\
\hline
\end{tabular}

Fonte: Dados coletados pelos autores.

Entre as respostas à pergunta “o que é mais interessante na instituição?”, os termos que apareceram com maior frequência foram "disciplinas técnicas", "conhecimento" e "amigos". Esses dados demonstram satisfação da maior parte dos estudantes em relação ao curso técnico que escolheram. Em relação à pergunta "o que é menos interessante na instituição?", a resposta mais frequente foi “disciplinas humanas”, demonstrando que a maior parte dos alunos apresenta preferência pelas disciplinas das áreas vinculadas às ciências exatas. As respostas de muitos alunos também apontaram o termo "aulas monótonas".

A maior parte dos estudantes interpelados (62,3\%) acredita que a Química tem importância nas suas vidas, mas apenas $20 \%$ explicitaram algum motivo que justificasse essa crença. O fato de boa parte dos sujeitos não conseguir perceber e/ou explicar a importância que a referida área do conhecimento tem para as suas vidas pode ser decorrente, ao menos em parte, da falta de conexões estabelecidas entre esta e o cotidiano durante suas vivências escolares pautadas por aulas tradicionais (FERNANDES; MEGID-NETO, 2012).

Com o uso do questionário, a professora-estagiária buscou não só conhecer mais sobre a vida dos estudantes, como também entender o que estes pensavam sobre o tema que seria 
trabalhado em sala de aula. Com isso, poderia iniciar o planejamento de sua ação docente tendo clareza sobre o pensamento de senso comum dos sujeitos, bem como traçando estratégias adequadas para trabalhar os conhecimentos científicos necessários à compreensão crítica do tema (FREIRE, 1987). Com isso, constatou que não havia, por parte dos integrantes das turmas, muito embasamento científico, nem familiaridade com termos e estruturas químicas. A estagiária apresentou reflexões sobre esse procedimento de coleta de dados, conforme o trecho abaixo (categoria 1 - investigação docente sobre as concepções prévias dos estudantes):

\begin{abstract}
Observei uma agitação quando leram a primeira pergunta ("O que é uma molécula?"). Possivelmente esta agitação deve-se a nunca terem parado para pensar sobre o significado da palavra molécula. Apesar disso, os alunos demonstraram, de um modo geral, ter boa compreensão sobre os conceitos de molécula e substância, sendo que a maioria respondeu, utilizando diferentes palavras, que uma molécula é um conjunto de átomos e que uma substância é um conjunto de moléculas. Porém, poucos alunos associaram o conceito de ligações químicas ao conceito de molécula. As perguntas 2 e 3, sobre alimentação, envolvem menos conceitos químicos e foram respondidas por todos os alunos. Muitos alunos citaram os conceitos "energia", "desenvolvimento do corpo" e "funcionamento do corpo" na pergunta 2, e utilizaram a palavra "balanceada" ao falar sobre alimentação saudável.
\end{abstract}

Dessa forma, o perfil das turmas foi identificado, o que orientou a elaboração dos demais planos de aula. O primeiro encontro com as turmas (dois períodos de 50 minutos com cada agrupamento - aulas 01 e 02) também possibilitou o desenvolvimento de atividades de ensino-aprendizagem introdutórias, que foram fundamentais para a continuidade do trabalho da estagiária. O planejamento destas está detalhado no Quadro 2.

Quadro 2 - Atividades desenvolvidas no primeiro encontro com as turmas.

\begin{tabular}{|c|c|c|}
\hline $\begin{array}{l}\text { Tópicos } \\
\text { da Aula }\end{array}$ & Atividades \& Conteúdos & $\begin{array}{l}\text { Estratégias } \\
\qquad \& \\
\text { Materiais }\end{array}$ \\
\hline 1 & $\begin{array}{l}\text { - Apresentação da professora e do roteiro da aula, também da forma } \\
\text { de avaliação e metodologia de trabalho. }\end{array}$ & $\begin{array}{l}\text { Diálogo, quadro } \\
\text { branco e canetas. }\end{array}$ \\
\hline 2 & $\begin{array}{l}\text { - Questionário para explorar os conhecimentos prévios dos alunos } \\
\text { sobre bioquímica e alimentos. } \\
\text { - Conteúdos Atitudinais: Reflexão sobre alimentação, acionando os } \\
\text { conhecimentos prévios. } \\
\text { - Conteúdos Procedimentais: Identificação dos lipídios, proteínas e } \\
\text { carboidratos, se possível. } \\
\text { - Conteúdos Conceituais: Conhecimentos sobre os nutrientes na } \\
\text { alimentação. }\end{array}$ & $\begin{array}{l}\text { Questionário } \\
\text { impresso entregue } \\
\text { aos alunos. }\end{array}$ \\
\hline 3 & $\begin{array}{l}\text { - Problematização inicial: Fazer algumas perguntas aos alunos } \\
\text { sobre o tema da aula e anotar as respostas no quadro. Tentar } \\
\text { construir um mapa conceitual a partir das respostas. } \\
\text { - Conteúdos Atitudinais: Participação nas discussões, empenho em }\end{array}$ & $\begin{array}{l}\text { Discussões em grupo, } \\
\text { utilizando o quadro } \\
\text { branco e canetas para } \\
\text { anotar as respostas }\end{array}$ \\
\hline
\end{tabular}




\section{\#tear}

\begin{tabular}{|c|c|c|}
\hline & $\begin{array}{l}\text { acionar seus conhecimentos prévios para trazer contribuições. Falar } \\
\text { perante a turma. } \\
\text { - Conteúdos Procedimentais: Compreensão do mapa conceitual. } \\
\text { - Conteúdos Conceituais: Neste momento da aula o aluno poderá } \\
\text { tomar consciência dos seus conceitos prévios a respeito de } \\
\text { alimentação. }\end{array}$ & $\begin{array}{l}\text { dos alunos e construir } \\
\text { um mapa conceitual. }\end{array}$ \\
\hline 4 & $\begin{array}{l}\text { - Formação de grupos de quatro ou cinco alunos e entrega de um } \\
\text { texto introdutório sobre alimentação, nutrição e dieta (com questões } \\
\text { para serem debatidas com os colegas e respondidas em grupo). } \\
\text { - Conteúdos Atitudinais: Participação nas discussões e } \\
\text { desenvolvimento de pensamento crítico sobre alimentação } \\
\text { saudável. } \\
\text { - Conteúdos Procedimentais: Interpretação de texto e identificação } \\
\text { das informações pertinentes. } \\
\text { - Conteúdos Conceituais: Compreensão do significado dos termos } \\
\text { alimentação, nutrição e dieta. }\end{array}$ & $\begin{array}{l}\text { Texto impresso } \\
\text { entregue pela } \\
\text { Professora estagiária. }\end{array}$ \\
\hline 5 & Fechamento expositivo da aula. & $\begin{array}{l}\text { Quadro branco, } \\
\text { canetas e materiais } \\
\text { impressos. }\end{array}$ \\
\hline
\end{tabular}

Fonte: Relatório da estagiária.

O tópico 4 da aula, mostrado no Quadro 2, foi um momento importante para fins de entendimento sobre o que pensavam os estudantes sobre a temática alimentação, além de possibilitar a interação entre estes, a construção de novos conhecimentos e a circulação das ideias através do diálogo. Para atividade proposta, os sujeitos deveriam ser reunidos em grupos, ler, interpretar e discutir um texto envolvendo o tema alimentação. As evidências indicam que a estagiária preocupou-se em explorar diferentes aspectos procedimentais e atitudinais no primeiro encontro com as turmas, não limitando as intervenções pedagógicas aos aspectos conceituais, que são igualmente importantes no contexto do ensino médio (POZO; CRESPO, 2009; VASCONCELLOS, 2008).

Para a correção das produções escritas decorrentes da atividade, a estagiária relata ter utilizado de uma estratégia baseada em critérios específicos (qualitativos e quantitativos) de interpretação das respostas dos estudantes. Em seu relatório, ao comentar sobre a referida aula, a estagiária mostrou-se satisfeita pelo bom aproveitamento dos estudantes (categoria 2 percepções sobre indicativos de aprendizagem apresentados pelos estudantes), destacando que o menor resultado quantitativo obtido pelos grupos, considerando todas as turmas interpeladas, foi de 8,5 pontos (sendo 10,0 pontos o máximo a ser obtido): "Esta atividade pareceu fácil para os alunos, que a realizaram rapidamente. A menor nota foi 8,5 " (fragmento extraído do relatório).

Para a elaboração do problema, foram utilizadas algumas prerrogativas das abordagens CTS (ciência, tecnologia e sociedade), construtivista e freiriana (esta já aprofundada na seção 


\section{\#tear}

2 deste artigo). Tal multiplicidade caracteriza as práticas docentes da estagiária como ações hibridizadas. Nas abordagens CTS e freiriana, busca-se a formação de um cidadão através do desenvolvimento de consciência social, o que suscita, dentre tantos outros elementos contemporâneos, a temática "alimentação saudável” (FAHL, 2003; FERNANDES; MEGIDNETO, 2012). O trabalho com problemas, por outro lado, traz aspectos da abordagem construtivista, incentivando que os alunos desempenhem um papel mais ativo na construção do próprio conhecimento, sob a orientação do professor (FAHL, 2003; FERNANDES; MEGID-NETO, 2012).

O problema proposto tem caráter qualitativo e semiaberto, uma vez que foram propostas perguntas variadas para orientar o andamento do trabalho (POZO; CRESPO, 2009). Além disso, o problema utilizado apresenta características da variante metodológica conhecida como "estudo de caso", uma vez que foi realizada uma contextualização e foram criados personagens com o objetivo de aproximar o enredo da realidade dos estudantes (SÁ; FRANCISCO; QUEIROZ, 2007; SOUZA; ROCHA; GARCIA, 2012). O problema (ou estudo de caso) que foi utilizado pela estagiária está apresentado no Quadro 3.

A sequência didática envolvendo a resolução de problemas foi adaptada da proposta de Leite e Afonso (2001), autores também citados por Freitas e Batinga (2015): $1^{\text {a }}$ fase: professor procede com uma ação investigativa, demarcando o contexto de interesse dos estudantes e, posteriormente, propondo um ou mais problemas; $2^{\mathrm{a}}$ fase: o papel do professor é orientar indiretamente o trabalho dos educandos, sem fornecer respostas completas e sem reduzir movimentos de aprendizagem discente (pesquisa, proposição e discussão de hipóteses ou sobre estratégias de resolução do problema). Aqui, há possibilidade de consulta a múltiplos materiais (livros, revistas, filmes, relatórios, dentre outros) e realização de atividades diversificadas, tendo em vista as exigências de cada problema (realização de experimentos, planejamento e execução de entrevistas, visitas técnicas, trabalhos de campo, dentre outros); $3^{\mathrm{a}}$ fase: de forma conjunta, docente e estudantes sintetizam e avaliam o trabalho realizado, tentando construir inferências sobre a solução apresentada ao problema proposto (se é viável, se efetivamente existe solução). 


\section{\#tear}

Quadro 3 - Problema (estudo de caso) proposto aos estudantes

\begin{tabular}{|c|c|c|}
\hline $\begin{array}{l}\text { Partes } \\
\text { do texto }\end{array}$ & Problema (estudo de caso) & $\begin{array}{l}\text { Objetivo de cada } \\
\text { parte do texto: }\end{array}$ \\
\hline $1^{\mathrm{a}}$ parte & $\begin{array}{l}\text { Ana é uma adolescente de } 17 \text { anos que estuda Eletrônica em uma escola } \\
\text { pública localizada no estado do Rio Grande do Sul. Em seu tempo livre, } \\
\text { Ana faz } 1 \text { hora diária de exercícios físicos, lê livros e estuda. } \\
\text { Recentemente, ela recebeu conselhos sobre alimentação de diferentes } \\
\text { pessoas, conforme descrito abaixo. } \\
\text { Colega de Academia: "Estou fazendo uma dieta na qual só posso comer } \\
\text { carne e ovos por algumas semanas. Nada de frutas, massas, arroz, batata, } \\
\text { legumes, bolacha, nem pão. Ouvi dizer que assim vou perder peso } \\
\text { rapidinho!". } \\
\text { Colega de Aula: "Tenho uma genética boa e posso comer de tudo, que não } \\
\text { engordo! Então, não controlo muito minha alimentação. Adoro comer } \\
\text { massa, pizza, pão com margarina, geleia e bolachinhas recheadas!". } \\
\text { Avó: "Pra comida ficar boa mesmo, tem que cozinhar com bastante banha } \\
\text { de porco". } \\
\text { Ana ficou confusa sobre qual seria a melhor forma de se alimentar, sendo } \\
\text { que seu objetivo é obter uma alimentação saudável. Você poderia ajudá-la } \\
\text { a entender todas dicas que ela recebeu e a forma mais saudável de se } \\
\text { alimentar? }\end{array}$ & $\begin{array}{l}\text { Apresentar o } \\
\text { contexto do caso a } \\
\text { ser estudado, } \\
\text { trazendo } \\
\text { elementos que } \\
\text { aproximassem os } \\
\text { estudantes do } \\
\text { enredo criado. }\end{array}$ \\
\hline $2^{\mathrm{a}}$ parte & $\begin{array}{l}\text { Para isso, pense nas seguintes questões: } \\
\text { - Quais as classes de moléculas presentes em maior quantidade nos } \\
\text { alimentos citados pela colega de academia, pela colega de aula e pela avó } \\
\text { da Ana? } \\
\text { - Qual é a estrutura química geral dessas moléculas? } \\
\text { - Qual é a função dessas moléculas no organismo do ser humano? } \\
\text { - De quais outros nutrientes o organismo humano necessita para manter } \\
\text { um bom funcionamento? } \\
\text { - Você vê algo de errado em alguma das dicas que a Ana recebeu? O quê? } \\
\text { Justifique. } \\
\text { - Qual conselho você daria para a Ana sobre alimentação saudável, } \\
\text { levando em consideração as respostas das questões acima? Você pode } \\
\text { fazer isso montando um cardápio alimentar adequado para um dia inteiro. }\end{array}$ & $\begin{array}{l}\text { Orientar o estudo } \\
\text { de aspectos CTS e } \\
\text { tornar explícitos } \\
\text { os conhecimentos } \\
\text { químicos } \\
\text { relacionados ao } \\
\text { caso. }\end{array}$ \\
\hline
\end{tabular}

Fonte: Elaborado pelos autores com base no relatório da estagiária.

Além dos problemas, os estudantes receberam materiais de apoio previamente revisados e adaptados pela estagiária. As fontes utilizadas foram reportagens disponíveis na internet, para que os alunos tivessem contato com esse tipo de material, que normalmente apresenta uma linguagem acessível a diversos públicos. Também foi indicado que os alunos utilizassem seu livro didático (SANTOS; MÓL, 2016) como fonte de pesquisa.

Os encontros da segunda semana da sequência de aulas apresentada foram realizados em um dos laboratórios de informática da instituição. Foram formados grupos (de três a cinco integrantes) e os estudantes puderam iniciar as discussões iniciais sobre o problema, a realização de pesquisas e a elaboração das resoluções por meio de um trabalho escrito e uma apresentação para os colegas. 
Segundo os relatos da estagiária, as aulas citadas foram muito produtivas. A maior parte dos alunos aproveitou o tempo disponibilizado para tentar construir soluções para o problema proposto, mostrando seriedade e boa aceitação em relação à metodologia. Abaixo, foi destacado um relato da estagiária sobre o desenvolvimento da atividade na turma $\mathrm{D}$ (categoria 3 - interesse dos estudantes):

\begin{abstract}
Pareceram se interessar muito pela situação-problema. Todos os grupos trabalharam no laboratório, me chamando, fazendo perguntas, preparando a apresentação. Vários grupos discutiam a situação como se fosse mesmo real, falando da personagem Ana como uma pessoa real. Trabalharam nos computadores até os últimos minutos de aula, e não percebi nenhum grupo fazendo outras atividades (como jogos). Também percebi que esta foi a turma que utilizou mais o material de apoio. As outras turmas o consultaram também, mas acabavam utilizando mais informações da internet.
\end{abstract}

Porém, também foram encontradas certas dificuldades/resistências de alguns estudantes, conforme pode ser observado no seguinte relato, a respeito da turma B (categoria 4 - resistência às atividades propostas):

Escutei diversas discussões sobre o tema alimentação e fui chamada para sanar
dúvidas diversas vezes, por grupos diferentes. Apenas um dos grupos não trabalhou
muito, sendo que utilizaram o computador para jogar. O grupo é constituído por
quatro alunos, os mesmos que conversam muito durante as aulas. Pedi para que
trabalhassem mais de uma vez mas, assim que eu me afastava, eles voltavam a jogar
ou a brincar entre eles. Com exceção deste grupo, acredito que a aula tenha sido
proveitosa.

A terceira semana foi reservada para a realização de uma aula expositiva e dialogada, com utilização de slides sobre alimentação e nutrientes (biomoléculas), havendo, ainda, momentos de resolução de exercícios. Pensando em uma sequência de momentos de aprendizagem com base na abordagem CTS (FERNANDES; MEGID-NETO, 2012), foram aprofundados os conhecimentos construídos nas aulas anteriores, sendo trabalhados conceitos químicos aliados a assuntos cotidianos (como biodiesel, gordura trans e saúde).

$\mathrm{Na}$ quarta semana, foram realizadas as apresentações das soluções que os estudantes encontraram para o problema (através de slides e uso de projetor multimídia). A maior parte das comunicações foi bem elaborada e mostrou que os integrantes de cada grupo se empenharam na atividade, realizando pesquisas e desenvolvendo pensamento crítico a respeito das relações entre os conhecimentos científicos e os aspectos sociais subjacentes ao tema, o que converge tanto com o modelo de ensino CTS, quanto com a perspectiva freiriana (FERNANDES; MEGID-NETO, 2012; FREIRE, 1987). O trecho apresentado abaixo demonstra a percepção positiva que a estagiágia teve em relação a tais ações, sendo referente 
aos seus relatos sobre a turma A (categoria 5 - aspectos positivos sobre o desempenho dos estudantes na apresentação das resoluções):

\begin{abstract}
Seis grupos apresentaram, e todas as apresentações foram muito boas. Percebi que a maioria deles consegue se expressar bem em público, o que pode significar que eles realizam apresentações com frequência. Todos os grupos montaram bem os slides, bem organizados e bonitos. Pude perceber também que eles realizaram pesquisas extras, para além dos materiais que foram fornecidos, sendo que as apresentações tinham um bom conteúdo. Fiquei realmente muito satisfeita com os trabalhos e com o empenho dos alunos.
\end{abstract}

A estagiária relata acreditar que o trabalho com a resolução de problemas tenha atingido o objetivo de estimular os alunos que, com o auxílio da docente, construíram novos conhecimentos ao longo do processo, de uma forma mais ativa, o que converge com a perspectiva construtivista planejada (FERNANDES; MEGID-NETO, 2012). Dessa maneira, os educandos vivenciaram diferentes momentos de aprendizagem que aparentam ter se afastado do modelo bancário descrito por Freire (1987).

Os relatos produzidos pela estagiária demonstram uma postura equilibrada, que não aceita as ocorrências da sala de aula de forma acrítica, havendo sempre ponderações acerca de pontos que poderiam ter sido conduzidos de forma mais satisfatória. Nesse sentido, pôde ser encontrada uma reflexão da docente em formação a respeito das apresentações dos grupos, conforme o trecho abaixo (categoria 6 - aspectos negativos sobre as apresentações das resoluções):

\footnotetext{
A única ressalva que faço é que achei que as apresentações ficaram repetitivas, uma vez que todos os alunos deveriam apresentar o mesmo trabalho. Percebi que alguns alunos também sentiram isso, sendo que alguns iniciaram suas falas dizendo "como os outros grupos já falaram". As apresentações foram distintas, sendo possível perceber que cada grupo realmente realizou seu trabalho, sem cópias. Porém, o assunto foi o mesmo para todos os grupos.
}

Outro ponto destacado pela estagiária, em seu relatório, foi a conexão de sua prática avaliativa com a consideração a respeito dos aspectos conceituais, procedimentais e atitudinais (categoria 7 - objetivos e instrumentos avaliativos). Nesse ponto, a professora em formação parece dialogar com diferentes interlocutores teóricos (LEMOS; SÁ, 2013; VILLAS BOAS, 2006), já que os cita em algumas passagens. As evidências tendem a mostrar que essa foi uma das tônicas do processo de desenvolvimento protagonizado pela estagiária, que discorre com bastante clareza a respeito dos aspectos a serem avaliados, bem como das formas pelas quais pretende obter informações acerca destes: 
A avaliação será feita de diversas maneiras, considerando os seguintes aspectos: Conceituais: A avaliação da aprendizagem será realizada através de uma prova escrita, feita em conjunto com a Professora titular, uma vez que a prova também abrangerá os conteúdos ministrados por ela. A resolução final para o problema também será entregue para a estagiária ou apresentada, sendo outra forma de avaliação. Para realizar esta avaliação, será levada em conta a evolução do conhecimento do aluno. Procedimentais: Esta avaliação será realizada durante todo o trabalho com a resolução de problemas, como nas discussões em grupo e na sistematização do conhecimento ao final desta atividade, onde será avaliada a capacidade dos alunos em formular hipóteses, interpretar textos e rótulos de alimentos e elaborar respostas. Atitudinais: Será avaliada a capacidade de trabalhar em grupo, o empenho na resolução do problema proposto e a capacidade de realizar reflexões críticas a respeito dos temas trabalhados. Esta avaliação ocorrerá durante todo o período de estágio, em todos os encontros com os alunos. Serão utilizadas avaliações formais, feitas a partir de provas e atividades documentadas, onde alunos e Professor sabem como e quando ela acontece, e avaliações informais, realizadas continuamente durantes as interações entre alunos e professores (VILLAS BOAS, 2006; LEMOS e SÁ, 2013). As avaliações serão utilizadas para conferir a aprendizagem dos alunos, com o objetivo de identificar e sanar dificuldades, pois a avaliação deve apontar o estágio de desenvolvimento em que o aluno se encontra, detectando suas dificuldades e possibilidades de avanço (LEMOS e SÁ, 2013).

Após a atividade de resolução de problemas, foi realizada uma avaliação escrita individual. A avaliação não objetivou examinar os alunos (classificar), mas produzir um diagnóstico que possibilitasse a reorientação das atividades propostas pela professora, conforme as necessidades apontadas pelos educandos (LUCKESI, 2011). Aqui, emergiram dois movimentos reflexivos do trabalho da professora-estagiária (o fragmento textual está abaixo).

Achei interessantes as respostas dos alunos à última questão da prova (A química
está presente em nossa alimentação? Onde/de que forma?), que foi onde eles
puderam demonstrar se realmente haviam feito uma conexão da química com o tema
alimentação. As respostas foram muito variadas, sendo que alguns alunos
conseguiram se expressar de maneira mais científica, enquanto outros utilizaram um
palavreado mais distante da química. Mas, de qualquer forma, a grande maioria dos
alunos demonstrou compreender a relaçãa que a química tem com a alimentação, o
que considerei uma vitória (...). A questão na qual os alunos apresentaram maior
dificuldade foi a que mais envolvia fórmulas estruturais, a questão 2, onde os alunos
tiveram dificuldades para identificar a ligação peptídica (sendo que apenas uma
aluna soube identificar a ligaçãa, e os demais alunos circularam partes da molécula).
Também foi observada a dificuldade dos alunos para identificar os grupos
funcionais existentes no fragmento de proteína, bem como para identificar quais
aminoácidos estavam presentes. Pretendo conversar com os alunos sobre as
dificuldades que apresentaram, uma vez que este é o principal objetivo de uma
avaliação, a reorientação do aluno.

No fragmento acima, há considerações sobre alguns elementos que indicam relativo bom aproveitamento dos alunos no instrumento avaliativo (novamente um fragmento que caracteriza a categoria 2 - percepções sobre indicativos de aprendizagem apresentados pelos estudantes). No segundo movimento reflexivo, igualmente retratado no fragmento acima, a professora torna mais explícita a descrição de algumas dificuldades conceituais apresentadas 
pelos estudantes (categoria 8 - inferências sobre dificuldades conceituais dos estudantes), bem como demonstra preocupação e projeta as providências que podem ser tomadas a partir dos resultados avaliativos que obteve.

Tendo em vista o conjunto de dados discutidos até aqui, inferimos que as oito categorias mencionadas tendem a identificar, ao menos em parte, os conhecimentos construídos pela estagiária. O relatório, como fonte única de dados, mostrou-se instrumento com múltiplas informações, abarcando reflexões profissionais da estagiária, bem como produções discentes decorrentes do trabalho docente no ensino médio de Química.

\subsection{Desafios que emergem das categorias}

Partindo das categorias identificadas, é possível elaborarmos algumas asserções de conhecimento para o campo da Educação em Ciências da Natureza, principalmente atrelada ao campo da formação docente, que serão consideradas como desafios aos atores atuantes direta ou indiretamente na Educação Básica. A categoria 1 - investigação docente sobre as concepções prévias dos estudantes - tende a reforçar o desafio de que os saberes dos sujeitos e as especificidades de suas comunidades sejam considerados como ponto de partida para o ensino-aprendizagem de conteúdos científicos. Nesse sentido, podemos evocar as pesquisas que envolvem representações de diferentes grupos de estudantes e diferentes objetos de representação que se relacionam com os saberes científicos (FONSECA, 2017). Esse desafio converge com a ideia de que a sala de aula pode ser pensada como lugar que articule a cultura cotidiana com a cultura científica.

A categoria 2 - percepções sobre indicativos de aprendizagem apresentados pelos estudantes - aponta para o desafio caracterizado nas práticas avaliativas desenvolvidas por professores da área de Ciências da Natureza, que normalmente estão baseadas em provas e valorizam a memorização de nomenclaturas, fórmulas e algoritmos de resolução de exercícios. O desafio é que as instâncias organizadoras dos cursos de formação inicial e continuada promovam e difundam, cada vez mais, a avaliação da aprendizagem que compreenda as características de ser: diagnóstica (busca entender o que os alunos aprenderam, justamente para possibilitar o planejamento de novas ações pedagógicas), processual (busca entender que a aprendizagem pode se dar ao longo do processo, sendo que o mais importante é oportunizar que os estudantes vivenciem diferentes momentos para que isso ocorra), dinâmica (os resultados das avaliações não significam um resultado definitivo, deve-se compreender que o aluno não pode ser considerado em estado estático em termos de aprendizagem), inclusiva/democrática (busca incluir todos os sujeitos no processo educativo, 
sem excluir aqueles que não aprenderam no tempo definido por parâmetros homogêneos, que não consideram as especificidades de cada estudante) e dialógica, pois está fundamentada na prática pedagógica que privilegia a interação entre os atores educacionais (LUCKESI, 2003, 2011; LEMOS; SÁ, 2013).

A categoria 3 - interesse dos estudantes - remete ao desafio que é, a cada dia de trabalho, enfrentado pelos professores da área de Ciências da Natureza. Conquistar a atenção do alunado parece ser uma das barreiras mais difíceis de serem transpostas pelos docentes e isso está diretamente relacionado às justificativas que são colocadas para as presenças de Química, Física e Biologia no currículo escolar. Sobre esse tópico, Millar (2003) apresenta reflexões que podem se tornar elementos fundantes para que os professores reflitam e orientem suas práticas na Educação Básica. Segundo o autor citado, existem justificativas fortes e fracas para a existência dos componentes curriculares das Ciências da Natureza nas escolas de ensino fundamental e médio.

Sobre as justificativas fracas, o autor ressalta que não bastaria, para motivar e envolver os alunos, afirmar que os conteúdos da área citada são importantes: para que o desenvolvimento econômico das nações seja consolidado (já que o número de especialistas a serem formados nessas áreas, necessários para a pujança econômica de qualquer nação, é limitado); pois a vida cotidiana exige a compreensão dos conceitos científicos (já que não é necessário entender os princípios científicos dos equipamentos tecnológicos disponíveis para uso da sociedade que, em sua maioria, é leiga em Ciências da Natureza); para participar das discussões democráticas da sociedade (já que, dado o grau de especialização que os diferentes ramos de pesquisa desenvolvem, se torna inviável a ideia de exigir compreensão aprofundada de um assunto como pré-requisito para participação nos debates públicos, quando estes envolvem temas variados relacionados às Ciências da Natureza).

Todos esses elementos, como salientado anteriormente, constituiriam argumentos fracos, ainda que figurem como justificativas presentes no âmbito da escola contemporânea. Por outro lado, assim como Millar (2003), defendemos a necessidade de que os professores da área de Ciências da Natureza, em seus contextos de trabalho, ensinem sobre a égide dos argumentos socioculturais considerados fortes: a ciência é uma aquisição fundante de nossa cultura, sendo que seu grau de relevância justifica a necessidade de que os jovens conheçam o potencial desse campo (a disseminação do conhecimento científico tornaria possível o estabelecimento de ligações mais eficientes entre as diferentes esferas da sociedade contemporânea, evitando o isolamento dos cientistas, seus objetivos, métodos e linguagens). 


\section{\#tear}

A categoria 4 - resistência às atividades propostas - acentua o desafio de que a questão da intersubjetividade e das táticas de resistências presentes nas salas de aula seja considerada como tema absolutamente necessário para a constituição de saberes profissionais dos professores. Nesse sentido, o desafio citado também exige que formadores de professores atentem para que essas discussões estejam presentes e potencializem a atuação de seus alunos. Conforme o estudo de Santos (2004), os espaços intersubjetivos são estabelecidos nos processos comunicativos (verbais e não verbais) entre os indivíduos, em sala de aula, promovendo interações que são fundamentadas em regras partilhadas entre os sujeitos.

Nesse sentido, pensando no trabalho docente, o primeiro passo para que se consiga construir um ambiente de ensino-aprendizagem é justamente aprender as estratégias que permitam construir espaços intersubjetivos adequados. Sendo um aprendizado prioritariamente prático (ainda que os elementos teóricos sejam também indispensáveis), os estágios de docência parecem ser um espaço privilegiado para que esses aspectos comunicativos sejam desenvolvidos e discutidos (convergindo com o apontamento feito no relatório de estágio que foi fonte documental desta pesquisa).

Intrinsecamente, o desafio de entender os processos de estabelecimento de espaços intersubjetivos requer conhecimentos de certas dinâmicas interativas muito próprias das salas de aula: as táticas de resistências discentes a propostas pedagógicas dos professores (SANTOS; MORTIMER, 1999). Segundo os autores citados, entre as maiores habilidades a serem conquistadas pelos docentes, tendo em vista a necessidade de construírem relacionamentos produtivos com os estudantes (harmoniosos e não conflituosos), figura a capacidade de negociar e firmar contratos de trabalho com os alunos. Tal postura, estando caracterizada pela abertura ao diálogo e à proximidade com os estudantes, pode evitar que os significados e valores propostos pelos professores sejam subvertidos por processos de resistência.

A categoria 5 (aspectos positivos sobre o desempenho dos estudantes na apresentação das resoluções) e a categoria 6 (aspectos negativos sobre as apresentações das resoluções), em conjunto, remetem ao desafio, presente no contexto de trabalho dos professores de Ciências da Natureza, de oportunizar que os estudantes sejam protagonistas das ações em sala de aula. Em outras palavras, seria o desafio de adotar elementos do modelo construtivista de ensinoaprendizagem: baseado em atividades que promovem a construção engajada de novas estruturas intelectuais, caracterizada pela motivação pessoal do aluno, na pesquisa e no trabalho em grupo, sendo que o professor atua como mediador dos processos que ocorrem no ambiente pedagógico (FERNANDES; MEGID-NETO, 2012). 
Tal desafio é amplo, pois requisita superação da estrutura vertical da relação professor-aluno (na qual o professor é visto como detentor do saber), bem como exige adequação reestruturante dos materiais didáticos tradicionais, normalmente distribuídos nas escolas. Além disso, torna-se necessário que as diferentes instituições de ensino básico favoreçam esse tipo de trabalho, possibilitando estrutura organizacional, partilha de experiências entre os docentes e momentos de formação continuada que tratem do tema. Essa perspectiva construtivista converge com as experiências narradas no relatório de estágio estudado neste trabalho, sendo que atividades com essa natureza foram convenientemente desenvolvidas pela professora estagiária citada ao longo deste texto.

A categoria 7 (objetivos e instrumentos avaliativos) e a categoria 8 (inferências sobre dificuldades conceituais dos estudantes) estão conectadas, novamente, à organização das atividades avaliativas, mas, nesse caso, com um enfoque no campo do currículo. Aqui, emerge um dos desafios mais prementes, que envolve o cotidiano das instituições escolares: a determinação dos conteúdos a serem trabalhados. Convergindo com o que é trazido pelo relatório da estagiária em tela, cabe ressaltar a necessária reflexão sobre quais seriam os conteúdos conceituais (significados de conceitos e princípios), procedimentais (métodos, técnicas e habilidades) e atitudinais (valores, atitudes e normas) a serem desenvolvidos com cada turma. Essa reflexão, acreditamos, perpassa todas as dimensões e sujeitos da comunidade escolar.

Segundo Zabala (1998), um ensino que se pretenda desenvolver através de uma abordagem construtivista, tal como discutimos anteriormente, está interessado na formação dos sujeitos de maneira integral, o que compreende um espectro mais global de suas capacidades, que são diversas entre si. Assim, não caberia restringir as atividades de ensinoaprendizagem de Ciências da Natureza (Química, no caso deste artigo), como faz o modelo de ensino tradicional, aos objetivos curriculares que abarquem, predominantemente, conteúdos conceituais.

\section{Considerações finais}

A análise do relatório de estágio discutido neste artigo propicia reflexões importantes a respeito dessa etapa da formação docente, principalmente no que tange ao contato da licencianda com o ambiente de trabalho dos professores (a infraestrutura, as lógicas de organização e os sujeitos), à experimentação de diferentes práticas de ensino e às críticas/reflexões realizadas a partir da observação de tais fatores (PIMENTA; LIMA, 2012). As oito categorias de análise que emergiram desta investigação demonstram que a licencianda 


\section{\#tear}

construiu aprendizados importantes, tendo a oportunidade de articular diferentes elementos teórico-práticos, o que não só enriqueceu as experiências da estagiária, como também possibilitou momentos de aprendizagem relevantes para os educandos da instituição de ensino onde foi realizado o referido período de regência.

As categorias citadas não foram adotadas como indicadores únicos, capazes de definir por completo o estágio realizado pela professora em formação inicial, mas como partes significativas de um processo complexo e envolto por aspectos, muitas vezes, intangíveis. Além disso, as categorias discutidas possibilitaram, no âmbito deste artigo, o diálogo com referenciais teóricos variados do campo educacional, principalmente na determinação de diferentes desafios que emergiram da investigação que desenvolvemos (sendo estes propostos aos professores da Educação Básica, professores formadores e instituições escolares), quais sejam: considerar os saberes dos educandos como ponto de partida para o ensino de Ciências da Natureza, estes sendo os protagonistas das atividades; que a avaliação da aprendizagem seja difundida através de suas funções essencialmente inclusivas e democráticas; que os currículos e práticas docentes sejam claros em termos das razões socioculturais que fundamentam a presença da área de Ciências da Natureza nos componentes curriculares da Educação Básica, dando subsídios para que o interesse do estudante seja conquistado de forma mais natural; que os saberes profissionais dos professores abarquem as questões de relacionamento, afetos e resistências presentes no ambiente escolar; que os conteúdos presentes nos currículos escolares (o que os alunos devem efetivamente aprender), sejam decididos a partir de um ponto de vista global, que abarque as múltiplas dimensões formativas e capacidades que a escola tem potencial para ajudar os sujeitos a construírem e desenvolverem.

A aprendizagem baseada em problemas mostrou-se uma ferramenta útil em aulas de Química e de boa aceitação entre os estudantes, modificando o seu papel de receptores de conhecimentos, passando a um papel ativo na busca e construção de novos saberes (POZO; CRESPO, 2009). A construção de conhecimento por parte dos educandos a respeito dos temas trabalhados pôde ser analisada ao longo de todas as etapas que envolveram a resolução do problema, bem como na avaliação escrita realizada. Da mesma forma, as maiores dificuldades dos sujeitos também puderam ser identificadas, tendo em vista um processo avaliativo que não objetivou a classificação dos indivíduos, mas a construção de um diagnóstico para reorientação das práticas (LUCKESI, 2003, 2011; LEMOS; SÁ, 2013).

Inferimos, assim, que o presente trabalho conseguiu atingir o seu escopo: foi possível relatar e problematizar parte dos aprendizados de uma estagiária de docência em Química, 
tendo em vista as reflexões produzidas por esta a respeito de suas práticas e vivências. Ademais, os resultados obtidos parecem dialogar diretamente com as temáticas da literatura contemporânea de formação de professores da área de Química (FONSECA; SANTOS, 2016), o que faz com que as análises, ora apresentadas, possam ser entendidas como potencialmente geradoras de reflexões para o contexto de outros sujeitos envolvidos com a pesquisa educacional ou diretamente com a docência.

\title{
PROBLEM-BASED LEARNING INVOLVING THE THEME FEED: REFLECTIONS ARISING FROM A STAGE IN CHEMISTRY TEACHING
}

\begin{abstract}
The present work has the objective of analyzing the practices and reflections of a chemistry trainee (Teacher Training Degree in Chemistry of the Federal University of Rio Grande do Sul), who was in a regency activity at a federal public school institution located in the metropolitan region of Porto Alegre - Rio Grande do Sul - Brazil. Problem-based learning methodology was used to work on the theme "healthy feed" with four classes of technical courses integrated to High School. An exploratory qualitative study was developed based on a single documentary source (the stage report produced at the end of the course) and the content analysis of the textual production was performed. Eight categories of analysis emerged from this research which gave indications that the training provided the teacher in the formation of relevant reflections regarding the teaching profession, mainly in relation to the experimentation of different teaching-learning practices and evaluation, taking into account the moments of construction of knowledge carried out by the subjects of the educational institution where the said regency period was held. From these categories some assertions of knowledge were built which were considered as challenges to be transposed by the subjects and institutions related to the area of Science Education.
\end{abstract}

Keywords: Problem-Based Learning. Healthy feed. Chemistry teaching. Teacher Education.

\section{Referências}

BATINGA, V. T. S.; TEIXEIRA, F. M. O que pensam os professores de química do Ensino Médio sobre o conceito de problema e exercício. In: VII Encontro Nacional de Pesquisa em Educação em Ciências, 2009, Florianópolis. Atas do VII ENPEC. Florianópolis: ABRAPEC, 2009.

ESTEBAN, M. P. S. Pesquisa qualitativa em educação: fundamentos e tradições. Porto Alegre: AMGH, 2010. 288 p.

FAHL, D. D. Marcas do ensino escolar de ciências presentes em museus e centros de ciências: um estudo da Estação Ciência do MDCC. Dissertação de Mestrado, Faculdade de Educação, Universidade Estadual de Campinas, Campinas, 2003. 
FERNANDES, L. dos S.; CAMPOS, A. F. Tendências de pesquisa sobre a resolução de problemas em Química. Revista Electrónica de Enseñanza de las Ciencias, v. 16, p. 458$482,2017$.

FERNANDES, R.C.A.; MEGID-NETO, J. Modelos educacionais em 30 pesquisas sobre práticas pedagógicas no ensino de ciências nos anos iniciais da escolarização. Investigações em Ensino de Ciências, v. 17, n. 3, p. 641-662, 2012.

FONSECA, C. V.. Articulações do Educar pela Pesquisa com a Teoria das Representações Sociais: uma proposta possível para o espaço da aula de Química no Ensino Médio Integrado. Experiências em Ensino de Ciências, v. 12, p. 35-60, 2017.

FONSECA, C. V. Química, nutrição e ensino médio: produção de material didático no enfoque das representações sociais. 2010. Dissertação de Mestrado, Instituto de Química, Programa de Pós-Graduação em Química, Universidade Federal do Rio Grande do Sul, Porto Alegre, 2010.

FONSECA, C. V. A formação de professores de química em instituições de ensino superior do Rio Grande do Sul: saberes, práticas e currículos. Tese de Doutorado, Faculdade de Educação, Programa de Pós-Graduação em Educação, Universidade Federal do Rio Grande do Sul, Porto Alegre, 2014.

FONSECA, C. V.; LOGUERCIO, R. de Q. Conexões entre química e nutrição no ensino médio: reflexões pelo enfoque das representações sociais dos estudantes. Química Nova na Escola, v.35, n.2, p. 132-140, 2013 a.

FONSECA, C. V.; LOGUERCIO, R. de Q. Representações sociais da Nutrição: proposta de produção de material didático de Química. Investigações em Ensino de Ciências, v. 18, p. 407, $2013 b$.

FONSECA, C. V.; SANTOS, F. M. T. Educação em química, formação e trabalho docente: revisão de pesquisas brasileiras (2002-2015). Investigações em Ensino de Ciências, v. 21, p. 179-199, 2016.

FRANCO, M. L. P. B. Análise de Conteúdo. 3. ed. Brasília: Líber Livro Editora, 2008.

FRANÇA, A. C. G.; MARCONDES, M. E. R. M.; CARMO, M. P. Estrutura atômica e formação dos íons: uma análise das ideias dos alunos do $3^{\circ}$ ano do Ensino Médio. Química Nova na Escola, v. 31, n. 4, p. 275-282, nov. 2009.

FREIRE, P. Pedagogia do oprimido. Rio de Janeiro: Paz e Terra, 1987.

FREIRE, P. Pedagogia da autonomia: saberes necessários à prática educativa. São Paulo: Paz e Terra, 1996.

FREITAS, A.P. ; BATINGA, V. T. S. Tendências de pesquisa sobre a Resolução de Problemas em Química no Encontro Nacional de Pesquisa em Educação em Ciências. In: X Encontro Nacional de Pesquisa em Educação em Ciências, Águas de Lindoia, Anais, 2015.

GUBA, E. G.; LINCOLN, Y. S. Effective Evaluation. San Francisco: Jossey Bass, 1981. 
LEITE, L.; AFONSO, A. Aprendizagem Baseada na Resolução de Problemas. Características, organização e supervisão. Boletín das Ciencias,v.16, n.48, p. 253-260, 2001.

LEMOS, P.S.; SÁ, L.P. A avaliação da aprendizagem na concepção de professores de química do Ensino Médio. Revista Ensaio, v. 15, n. 3, p.53-71, 2013.

LUCKESI, C.C. Avaliação da aprendizagem na escola: reelaborando conceitos e recriando a prática. 7 ed. Salvador: Malabares Comunicação e Eventos, 2003.

LUCKESI, C.C. Avaliação da Aprendizagem: componente do ato pedagógico. São Paulo: Cortez, 2011.

LÜDKE, M.; ANDRÉ, M. Pesquisa em educação: abordagens qualitativas. São Paulo: EPU, 1986.

MILLAR, R. Um currículo de ciências voltado para a compreensão por todos. Ensaio Pesquisa em Educação em Ciências, v. 5, n. 2, p. 146-164, dez., 2003.

PIMENTA, S. G.; LIMA, M. S. L. Estágio e Docência. 7. ed. São Paulo: Cortez, 2012.

POZO, J. I.; CRESPO, M. A. G. A aprendizagem e o ensino de ciências: do conhecimento cotidiano ao conhecimento científico. 5. ed. Porto Alegre: Artmed, 2009. 296 p.

SÁ, L. P.; FRANCISCO, C. A.; QUEIROZ, S. L. Estudos de caso em química. Química Nova, v. 30, n. 3, p. 731-739, mar. 2007.

SANTOS, F. M. T.. A Criação e Manutenção da Intersubjetividade na Sala de Aula de Química. Investigações em Ensino de Ciências, v. 9, n.3, p. 1-21, 2004.

SANTOS, F. M. T.; MORTIMER, E. F. Estratégias e Táticas de resistência nos primeiros dias de aula de Química. Química Nova na Escola, v. 10, n.10, p. 38-42, 1999.

SANTOS, W.; MÓL, G. Química Cidadã. v. 1. 3. ed. São Paulo: AJS, 2016.

SOUSA, R. S.; ROCHA, P. D. P.; GARCIA, I. T. S. Estudo de caso em aulas de química: percepção dos estudantes de nível médio sobre o desenvolvimento de suas habilidades. Química Nova na Escola, v. 34, p. 220-228, nov. 2012.

VASCONCELLOS, C. S. Planejamento: Projeto de Ensino-Aprendizagem e Projeto Político-Pedagógico. São Paulo: Libertad, 2008.

VILLAS BOAS, B. M. Portifólio, avaliação e trabalho pedagógico. Campinas: Papirus, 2006.

ZABALA, A. A prática educativa: como ensinar. Porto Alegre: Artmed, 1998. 